\section{Más allá de las}

Lenguas Nacionales: Interlengua y

Vocalizaciones de la

Migración*

Beyond the national languages:

Interlanguage and migration voice

Jorge Ignacio Cid Alarcón

* Este artículo ha sido producido en el marco de la investigación ANID/CONICYT FONDECYT Iniciación $\mathrm{n}^{\circ} 11180374$, titulado "Crear/se y publicar/se en la periferia: un estudio comparado de colectivos poéticoculturales actuales de Brasil, Argentina y Chile", del que soy investigador responsable

Recebido em: 25 de julho de 2020

Aceito em: 30 de agosto de 2020
Jorge Cid es académico de la Universidad Adolfo lbáñez y Docteur en Langue et Littérature Romane por la Université de Poitiers. Ha editado Una lengua en trance: Carmen Berenguer y Reynaldo Jiménez, poetas que nos interpelan y coeditado Contrarreforma Católica, implicancias sociales y culturales (Cuarto Propio, 2019). Como poeta ha publicado Labia Larvaria (Universidad de Concepción, 2009) y Éxodos (Cástor y Pólux, 2019).

Contato: jorgeignaciocid@gmail. com

Chile 
PALABRAS CLAVE:

Heteroglosia; Interlengua; Poesía; Neobarroso; Néstor Perlongher.

KEYWORDS: Heteroglossia; Interlanguage; Poetry; Neobarroso; Néstor Perlongher.
Resumen: Este artículo reflexiona sobre cómo la poesía de Néstor Perlongher integra en su lenguaje elementos heteroglósicos y las consecuencias que éstos, en tanto que gestos de inobservancia gramatical, tienen en el plano simbólico y político. Obras como Alambres de Néstor Perlongher (escritos mezclando portuñol, lunfardo y gauchesca) parecen rebelarse contra la forma en que la sramática, más allá de regular la correcta realización de un idioma, instituiría un dispositivo de control de la emotividad de los individuos a través del establecimiento de formas de expresión homoseneizantes propendidas por la lengua materna en su manifestación estándar. En este contexto, la utilización de mecanismos heteroglósicos en la creación literaria permite al poeta combatir la matrificación de la subjetividad que comportan las lenguas de Estado, instaurando la desestabilización de sus paradigmas fronterizos a través de la transgresión de sus estatutos idiomáticos.

Abstract: This article reflects on the way in which Néstor Perlongher's poetry integrates, in his language, heteroglossic elements and its effects at the symbolic and political level. We will analyze his work Alambres written mixing Portuñol, Lunfardo and Gauchesca, rebelling against grammar as a linguistic norm and device for controlling the emotionality of speakers of the standardized mother tongue. In this context, the use of heteroglossic mechanisms in literary creation allows the poet to combat the matrification of subjectivity that State languages carry, establishing the destabilization of their border paradigms through the transgression of their language statutes. 


\section{Hacia una INTERLENGUa neObarrosa}

Perlongher conecta su poesía con hablas no oficiales, operativas al margen de la gramática, configurando cuerpos mediante la multiplicidad de voces que convergen en su enunciación. Esta experiencia se desarrolla mediante la construcción de una suerte de interlengua la que ha sido definida por la didáctica de lenguas como "el sistema lingüístico del estudiante de una segunda lengua en cada uno de los estadios sucesivos de adquisición por los que pasa en su proceso de aprendizaje." (Centro Virtual Cervantes, 2012). Este concepto describe el estado de constante dinamismo en el que el hablante desarrolla sus competencias lingüísticas en una lengua secundaria o terciaria y cómo en dicho proceso son descritos diversos estadios de logro.

La utilización de este concepto resulta útil para caracterizar la escritura neobarrosa, en la medida en que su enunciación puede ser entendida como el proceso de aprendizaje de un lenguaje que se desplaza hacia diversas variantes idiomáticas distintas del español estándar. Esta suerte de proceso simultáneo de aprendizaje de diversas lenguas se caracterizaría por dar lugar a interferencias lingüísticas de lenguas secundarias y terciarias. A continuación, observaremos como éstas se van sucediendo en el poema perlonghereano, realizando una conjuración sistemática de presencias que recomponen la historia de un trance corporal a través de otro trance de carácter lingüístico. Con este fin, comentaremos el poema "El rompehielos"

1 Algunos contenidos desarrollados en este artículo retoman y desarrollan aspectos tratados en mi artículo, en mi tesis doctoral "Nestor Perlongher: Hacia una poética del trance", dirigida por Fernando Moreno Turner en la Université de Poitiers. 
prestando particular atención a la implementación de una interlengua poética. Este poema pertenece al libro Alambres, particularmente a la sección reunida bajo el título de Frenesí. Este libro corresponde al que hemos entendido como el primer capítulo de la obra perlonghereana, en el que la explotación de una textualidad histórica resulta particularmente ostensible.

Ahora bien, la sección a la que pertenece este poema se constituye por otros dos poemas que funcionan como un adelanto del gradual oscurecimiento que caracterizaría los dos libros siguientes, Hule y Parque Lezama, en la medida en que, en ellos, se observa una proliferación neobarrosa que determina un notorio corte con el plano semántico. Sintomáticamente, los poemas que acompañan a "El rompehielos", se titulan "carnaval - río 1984" y “(el rigor de la histeria") realzando, de este modo, su conexión con la fuerza del carnavalismo y la enfermedad.

Nos parece importante analizar este poema por la riqueza que comporta su carácter fronterizo entre la serie de poemas neobarrosos que trabajan la reescritura de la historia de manera directa - principalmente Austria-Hungría y Alambres - y la producción sucesiva en la que se da rienda suelta a una experimentación intensiva de lenguaje neobarroso. En el caso de este poema, el título parece constituir una referencia bélica al rompehielos Irízar que participó en la Guerra de Malvinas², conectando, así, su enunciación con la historia argentina inmediata.

2 Datos extraídos de: Hedelvio, Laurio. 100 años de un rescate épico en la Antártica. Buenos Aires: Instituto de Publicaciones Navales, 2003. 
El poema consta de tres estrofas de diecisiete, veinte y veintiún versos, respectivamente, a las que se suma una nota al pie de página en la que se entrega la definición -que, según corroboramos, coincide con la definición propuesta por el Diccionario de la RAE- de la palabra "Sotrozo: Art. Pasador de hierro que atraviesa el pezón del eje para contener la rueda de la cureña" (Poemas 113). La eventual intención clarificadora que puede sugerir la integración de esta definición al poema queda descartada ante la evidente presencia de muchas otras palabras de origen y significado de difícil determinación, según constataremos en lo sucesivo. Su inclusión corresponde más bien, según nos parece, a un señuelo de didactismo.

En cuanto al aspecto léxico, reconocemos que, en un universo de 664 palabras, al menos veintiuna de ellas son asociables al portugués y dieciocho al lunfardo, lo que refleja una utilización más o menos equilibrada de ambos sustratos en el interior del texto. Las palabras en portugués parecen, en ocasiones, responder a la transcripción fonética del portugués en español, como en el caso de lingüiza que puede ser entendida como la pronunciación figurada de la palabra portuguesa lingüiça, que se refiere a un embutido "Chouriço delgado de carne de porco" -, que se utiliza en la expresión "encher lingüiça”, cuyo significado actual equivale a la expresión castellana "hablar hasta por los codos", en alusión a quien hablar demasiado y vanamente.

El ejemplo anterior es sólo el primer ejemplo de una larga lista de fenómenos que se manifestaron regularmente en la escritura neobarrosa y que podríamos describir como el desapego sistemático de un ejercicio normado de la lengua. En esta misma línea, se observa la utilización de 
figuras de transformación, de adición y eliminación. En este poema en particular advertimos al menos dos aféresis: ornicar y asgadas. En estos casos se ha suprimido la letra f y r, respectivamente. Este fenómeno abre una interesante complejidad en la que el equívoco aparente es señal de una significación ambivalente que se extiende tanto al español como al portugués.

Tanto en el caso de estas aféresis, como en el caso de la escritura espańolizante de la palabra lingüiça, nos encontramos frente a lo que podría ser entendido, pensando la poética del trance como una interlengua, como un fenómeno de fosilización. Este ha sido advertido en los casos en los que "el aprendiente mantenga en su interlengua, de manera inconsciente y permanente, rasgos ajenos a la lengua, meta-relacionados con la gramática, la pronunciación, el léxico, el discurso u otros aspectos comunicativos.". (Centro Virtual Cervantes, 2012).

Esta actitud, que pareciera no ser aplicable en el caso de los errores cometidos en espańol, por ser ésta la primera lengua del poeta, resulta de gran relevancia en la medida en que estos parecen describir el deseo de volver extranjera la enunciación al interior de su lengua materna. Una de las razones que explican la fosilización es la falta de deseo de aculturación, situación en la que parecería estar Perlongher, pero no frente a una lengua secundaria sino que, paradójicamente, frente a la lengua dominante. Lo anterior se sustenta en que el comportamiento poético de la escritura perlonghereana parece responder a un proceso de extrañamiento extremo en el que el hablante se resiste por diversos medios a permanecer en el logos dominante de su lengua y cultura. Es precisamente en este momento en el que se vuelve simbólicamente 
relevante la observación de la interacción de la lengua dominante con lenguas de menor prestigio.

Más adelante, se observa en el poema el caso de la palabra respostar ${ }^{3}$, que parece corresponder a una epéntesis del verbo repostar que ha sido definido como: "1. tr. Reponer provisiones, pertrechos, combustibles, etc, u. t. c. prnl. El acorazado fondeó para repostarse."’ (RAE, 2012) que, por este ejemplo integrado a la definición, podríamos vincular al campo semántico del rompehielos que sirve de título al poema. Ahora bien, si enfrentamos la palabra respostar desde la perspectiva de la interlingualidad explotada por Perlongher, sometiéndola a la sospecha de su extranjería, confirmamos que quiere decir en portugués "responder incivilmente" (Priberam, 2012) 5 . De este modo, lo que en una primera lectura se apreciaba como una epéntesis, constituye, desde un enfoque interlingual, la muestra de un influjo portuńolizante.

En diversos poemas de Perlongher se registran figuras transformativas de adición y/o eliminación, así como también de modificación como la metátesis. Éstas tienen como consecuencia el paso de una palabra desde el español hacia el portugués. Esta situación nos lleva a pensar que la disponibilidad léxica perlonghereana busca poner de relieve la relación de opacidad y transparencia

3 El análisis de las figuras transformativas de adición y/o eliminación relativas al poema "El rompehielos" retoma algunas consideraciones expuestas a modo de ejemplo en mi artículo "Apuntes de filiación neobarroca sobre La mujer desnuda de Armonía Somers", en La escritura de Armonía Somers. Pulsión y riesgo, publicado por Ediciones de la Universidad de Sevilla en 2019.

4 Disponible en: http://lema.rae.es/drae/?val=repostar. Consultado el 8 de noviembre de 2012.

5 Disponible en: http://www.priberam.pt/dlpo/default.aspx?pal=respostar. Consultado el $10 \mathrm{de}$ noviembre de 2012. 
del portugués en el español y viceversa. Resulta importante la observación meticulosa de estas variaciones puesto que, en general, el contexto versicular no aporta información relevante que permita anticipar la aparición de una palabra ajena al español estándar.

A continuación, presentamos las tres estrofas del poema "El rompehielos" con el fin de observar la distribución y disposición de los elementos heteroglósicos en el texto. Con este fin se han destacado en negrita las palabras asociadas al portugués y en subrayada las provenientes del lunfardo ${ }^{6}$ :

Alud del aludir: el respostar, reposteril membrana, en el calambre, nítido o níveo, la renda en la gargola, la gárgara de rendas, el gorgotear del pelandrún en la marisca de sofocos, puercoespín, himenil, el piecesillo de Farabeuf -cuando, al piscar, al ornicar. hacía hablar a los peces azules, colorados-, el truco estaba

6 Es importante precisar que entendemos el lunfardo como un corpus lingüístico dinámico, no necesariamente circunscrito al ámbito del hampa como indica cierto lugar común (claramente influido por su primer contexto de desarrollo y registro), sino que como una jerga irradiada a la sociedad y jalonada por su inclusión en producciones culturales como la literatura y el tango, en los términos en que lo propone Gerardo Augusto Lorenzino en su trabajo "El lunfardo en la evolución del español argentino": "La inmigración a la Argentina creó las condiciones sociales de marginalidad (delincuencia, criminalidad), para la aparición del lunfardo o jerga especial de los ladrones, el cual, una vez difundido a toda la sociedad, recorrió los mismos cambios semánticos que afectan el vocabulario de toda lengua de uso general, tal como lo ejemplifica la pérdida de la asociación restrictiva a la vida del hampa en el vocabulario del corpus. Esta variedad "descriminalizada" del lunfardo devino - junto a los italianismos del cocoliche - en un componente del español porteño del presente. Con el tiempo, el lunfardo fue superando las estructuras y fronteras sociales impuestas por la sociedad clasista, convirtiéndose en la vertiente incondicional, niveladora e identitaria del habla de los argentinos y, como la cenicienta de la comunicación, forma parte de la literatura de autores canónicos argentinos como Robert Arlt, Julio Cortázar y Jorge Luis Borges. Un fiel indicador de la valoración e influencia del lunfardo en el lenguaje argentino es la existencia de la Academia Porteña del Lunfardo, que celebra todos los 5 de septiembre el Día del Lunfardo.” Este artículo fue publicado en Literatura y Lingüística, Santiago, n. 34, p. 335-356, 2016. Disponible en: <https://scielo.conicyt.cl/scielo.php?script=sci_ arttext\&pid=S071658112016000200016\&lng=es\&nrm=iso $>$. Consultado el 30 ago. 2020. 
en el tricot de la cadera, en el tricostelón de la Nigeria, acantilar atlántida del oso lenguaraz. El caracol, por darle verme al ristre. La sotreta, recamada de alubias, alicia lesa en una elipsis demasiado estirada, comisura del rictus, come y sura. El huracán del buscapié y el tornado mujer, la brizna del sostén en el pajareo incontenible, el pico al piel del novio y remirándola la prímula, gorgoreo de rusas, engomadas arábigas. Listar del broderie el entusiasmo, intuito del fiestero, algozador las lenguas se le hacen medias (o inmedias) como estambres. Firuletea el rompehielos, guińa al esguince del sotreta montado, soterrado, sotrozo* de fintas en el reiterarse legañosa, en la grandilocuencia del ventrílocuo vecinal, barrado.

Retornar, rocelar de la ligustrina maniatera, cuyo buril era apagado por una constelación de vidrios focos, de vidrieras rumanas vampirizando el "volga va ". Ya vista, la lechuza cairelábase en el menstruar de efebos de azabache, lame el carmín lunares de ballesta. El fechado, al saltar, de los linces el linde pajueril, rímini hosco y limosnero, cernía la cariátide de los atletas en una tirria resinosa, bocina de carbunclo, amarilleante colomí en la lingüiza. La lengüeta, por no el zapato postular, acariciaba en la sordina el ganglio de los africados, rizado ríe del agror por una rima tan deseada. Y Lita: lituana espúrea - que da a nueve, en el cerbanatar, prurito la congoja, paspa el canto. Rúe, porque unas vestes aún ampáranla. Cosida, ya que bretel el cancro, lustre el fimo. Sinuosidad de la cerveza, el quicio rebanaba corrales, apios torcidos en el camandulear, contestados condones. Y donceles, y brotados. ¿Coordinar para el torvo la nalguicie, vallejo urdir la fístula luzbélica, y por candir fosforecer el hurto, las "entrañas" asgadas -palafrenero del esfínter en la borbota carmesí? El agudo, si aguado, levitaba al pendor la córnea blanda, íntima. Fosforescencia y glauca. El vegetal, cogido por el níspero, cruza delfines con venablos.

Le daba al africado, pirulera, el cerúleo candor, maromas de aduanera, en el dejar pasar de la congonha por la estría porosa. Le preguntaban si había venido de hidroavión para medir el peso de sus 
glúteos, el fibroma de cincuenta libras bajo los cambaceres del tulcito, leonel mirón de pie en la leonera o liorna de los monos semidesnudos, depilados, la cera negra de Treblinka en el tremor timbrado de la flema. La gema, chal de felpa, yeminal, al conjuro de las malaquitas traicionaba la dureza, ya glacial, del derrame, en la refistolería de morados y milhos verdes, pirateados por el malandro en la boca del subte semienterrado, semicorredizo por los ojos de buey de los cinturones y los bagres pintados en la costa con calcomanías de carey. Repujados, altivos. Contorsionistas del desfile, el paseo de los caimanes en la bandolera resinosa. El picoteo de las madréporas en los collares del Vesuvio, el efluvio de pinga en el pingote ('me acarició la yema") las borrachas, flexibles, gárrulas, limosas en el fluxo del glande, el fijador acuoso de pegaso lujar. o iglesinesco, lie lioneras de azulejos con polvo de canarios, o de albatros, pájaros prietos en un fondo de cielo azorado. Al azotarla, al blandir la excrecencia pegajosa, la creciente, la ceceosa esmeralda, rotulaba con el blandor de la alegría la estría del goloso, sollozante y fugaz jubiloso. Hazmerreír, de pantas y palmeras, la nevera del bánalo en el banal-tambor, el repicar de los badajos en los goteos (acueductos) de una furiosa farsa.

(Perlongher, 1997, 113)

Es posible constatar que se trata de un poema en el que la función musical del lenguaje tiene gran relevancia en desmedro de la función comunicativa. Lo anterior se logra, por ejemplo, en el caso de los seis primeros versos, gracias a la alternancia rítmica de fonemas vibrantes simples y múltiples con oclusivos sonoros. Los fenómenos de transformación aquí observados constituyen un guiño a la oralidad y, más específicamente, a sus procedimientos generativos. En esta línea, observamos en el caso del lunfardo los siguientes ejemplos de aféresis: "tungo" para referirse a "matungo", palabra que sirve para referirse al caballo, "tano" para hablar 
del "napolitano", "rante" en lugar de "atorrante" o "fiolo", que funcionaría como aféresis de "cafiolo", entre muchos otros ejemplos?

Dada la cercanía etimológica de las lenguas española y portuguesa, el error en la escritura puede constituir una especie de vaso comunicante entre ambas, posibilidad que Perlongher aborda en su escritura. La plasticidad de su enunciación guarda relación con la flexibilización de la norma gramatical producto de la preponderancia que tuvo en el trabajo escritural de Perlongher la observación de las jergas y variantes de la coloquialidad.

Ahora bien, en cuanto al vocabulario lunfardo utilizado en el poema podemos distinguir que se especializa en palabras que refieren a personas ligadas al mundo delictual tales como: lince, palabra con la que se refiere al ladrón de buena vista; limosnero, como se califica al maleante especializado en sustraer dinero de alcancías de iglesias; bandolero, como se llama al salteador de caminos que robaba en lugares despoblados y solía pertenecer a una banda ${ }^{8}$.

Del mismo modo, encontramos palabras del lunfardo que sirven para describir cualidades negativas de personas tales como: oso, término con el que se refiere a alguien indiferente, que se desentiende de algo, sotreta, que significa canalla, mentecato, utilizado originalmente para referirse al caballo inútil por sus mañas, y luego aplicado al hombre de similares características. Esta palabra, existente también en el portugués con acepciones equivalentes,

7 Estos ejemplos han sido extraídos de: Gobello, José. Nuevo diccionario lunfardo. Buenos Aires: Corregido, 1999.

8 Estas definiciones, así como las que continúan, han sido rescatadas del Diccionario de términos lunfardos, gauchescos, jergas y modismos argentinos Que Significa. [Consultado el 8 de diciembre de 2012], http//www.que-significa.com.ar 
se convierte en un buen ejemplo de cómo las fronteras territoriales actuales no logran circunscribir de manera restrictiva sus léxicos, sugiriendo, de este modo, formas subterráneas e inesperadas de irradiación de la cultura.

En la misma línea, encontramos el término bagre, forma despectiva para referirse a una mujer fea y despreciable, así como pingo que, al mismo tiempo que refiere a un caballo y al sexo masculino, habla de la mujer casquivana. Del mismo modo, se hace referencia a actitudes sospechosas y/o confusas como camandulear, que hace referencia a "andar con tapujos y evasivas para decir las cosas / corretear, chismear, enredar, trabar/ ser hipócrita o taimado, ostentar falsa o exagerada devoción", firuletear, que significa hacer "pasos complicados en un baile para lucimiento/ presumir de elegante con adornos impropios o ridículos", hacer finta que refiere al "Amago que se hace con intención de engañar [...] parada que hace un cuchillero para engañar al contrario y ubicarle el golpe en otro sitio".

Las palabras en portugués no se circunscriben a un campo tan acotado como los dos que acabamos de mencionar en el caso del lunfardo, sin embargo, se observan ámbitos de referencia en los cuales se reúnen las dos lenguas hasta aquí pesquisadas. Tal es el caso de la enfermedad a la que refieren las palabras carbunclo del lunfardo y marisca del portugués. En el primer caso se refiere a la "enfermedad virulenta y contagiosa, frecuente y mortífera en el ganado lanar, vacuno, cabrío y, a veces, en el caballar. Es transmisible al hombre, en el que se denomina ántrax maligno, y está causada por una bacteria específica", mientras que en el segundo a la hemorroide externa. 
Así también, desde las dos lenguas se nombran partes del cuerpo como en el caso de pingo y badajo, provenientes de la jerga argentina, y lingüiça de origen portugués. En los tres casos, una de sus acepciones hace alusión al sexo masculino. Se encuentran además referencias a actos de violencia como al hablar del lustre, término con el que se alude a "agredir con el pie/ (pop.) Azotar, pegar, golpear, vapulear, zurrar.”, así como también referencias al truco "Juego de naipes de envite con cartas españolas, con 2, 3, 4, 6 u 8 jugadores con reglas determinadas y en el que se miente en gran medida, pudiendo realizarse señas entre los compañeros.”

La revisión de las palabras del lunfardo utilizadas en este poema coincide con lo apuntado por Morínigo en cuanto a que esta lengua sirve, particularmente, para construir campos semánticos vinculados con "la delincuencia, el vicio, la indolencia o de ocupaciones para paliar la pereza, como la de musicante ocasional, los juegos de azar, las carreras de caballos, la suerte de los naipes, sus trampas y fullerías" (Morínigo, 2005,101 citado por Klee, 2009, 190). Esto demuestra con claridad la idea de que la utilización de una lengua comporta la conjuración de sus hablantes y de sus formas de vida.

El poema comienza con la frase "Alud del aludir" (Perlongher, 1997, 113) sucedida por dos puntos como si el cuerpo del poema fuera su definición. La referencia al alud $-1 . \mathrm{m}$. Gran masa de nieve que se derrumba de los montes con violencia y estrépito. 2. m. Masa grande de una materia que se desprende por una vertiente, precipitándose por ella. U. t. en sent. fig. (RAE, 2012) ${ }^{9}-$

9 Disponible en: http://lema.rae.es/drae/?val=alud. Consultado el 08/05/2013. 
en relación con el título, insinúa la imagen del rompehielos quebrando los casquetes polares con el fin de abrirse paso. Este movimiento de ruptura y avance es reproducido musicalmente en el poema por medio de una rítmica y regular reiteración de sonidos.

El uso de una serie de aliteraciones otorga al poema una musicalidad trabada a la que asociamos el sonido del rompehielos atravesando, al mismo tiempo que la superficie antártica, el silencio de la página en blanco. La cuidada agrupación de consonancias silábicas en secuencias de dos o tres sonidos similares, dispuestos de manera casi contigua, se mantiene a lo largo de todo el poema. Observemos a continuación su recurrencia y distribución en la primera estrofa. Se han utilizado dos variedades de gris para diferenciar el cambio de sonido:

Alud del aludir: el respostar, reposteril membrana, en el calambre, nítido o níveo, la renda en la gargola, la gárgara de rendas, el gorgotear del pelandrún en la marisca de sofocos, puercoespín, himenil, el piecesillo de Farabeuf - cuando, al piscar, al ornicar, hacía hablar a los peces azules, colorados -, el truco estaba en el tricot de la cadera, en el tricostelón de la Nigeria, acantilar atlántida del oso lenguaraz. El caracol, por darle verme al ristre. La sotreta, recamada de alubias, alicia lesa en una elipsis demasiado estirada, comisura del rictus, come y sura. El huracán del buscapié y el tornado mujer, la brizna del sostén en el pajareo incontenible, el pico al piel del novio y remirándola la prímula, gorgoreo de rusas, engomadas arábigas. Listar del broderie el entusiasmo, intuito del fiestero, algozador las lenguas se le hacen medias (o inmedias) como estambres. Firuletea el rompehielos, guińa al esguince del sotreta montado, soterrado, sotrozo* de fintas en el reiterarse legañosa, en la grandilocuencia del ventrílocuo vecinal, barrado. (Perlongher, 1997, 113) 
La sucesión de rimas otorga movimiento y sentido al poema, que parece estar construido como evocación de un hecho sonoro. En efecto, este texto no dialoga con la historia en los términos en que esto tuvo lugar durante los primeros capítulos de la obra, sino que, más bien, como un diálogo con una historia musical, el registro de los sonidos que caracterizaron determinados eventos. No se trataría entonces de una crítica racional respecto de, por ejemplo, la pertinencia de la Guerra de Malvinas, sino que una polifonía incidental a la ruta seguida por alguno de los rompehielos que participó en ella.

Este juego de cacofonías da cuenta de un trabajo consciente del poeta en el plano fónico, que se suma al tránsito hacia los márgenes que llevó a Perlongher hacia otras lenguas y a la explotación de otras formas de sugerencia. Estos intentos convierten su escritura en una suerte de lengua imaginada, anexa a la realidad, al mismo tiempo que fugitiva de ésta. Su estatus de lengua artificial, al interior de lenguas de exilio y residuales, nos recuerda de alguna manera lo que Alfonso Reyes llamó jitanjáfora, aludiendo al neologismo propuesto por el poeta cubano Mariano Brull (Reyes, 2010), que él utilizara para hablar de los juegos de palabra cuya base era el sonido. Un ejemplo interesante en este sentido es la invención del gíglico por parte de Córtazar, especie de lengua, en apariencia carente de sentido, cuya plasticidad fónica queda de manifiesto al mismo tiempo que el texto sugiere un encuentro amoroso (Cortázar, 2004, 387). Resulta importante integrar a esta lista de lenguas poéticas los capítulos en que el neobarroso, como en el caso de "El rompehielos", se vuelve manifestación eminente del arte de hablar evadiendo el sentido, poniendo al lector bajo el influjo de una cadencia sugestiva. 
Este poema se vincula con hablas periféricas por medio de la utilización fragmentaria y la mímica que de ellas realiza en tanto que lenguas internas, de comprensión restringida a los miembros de una comunidad. Con esto no pretendemos negar la improbable existencia de una comunidad de hablantes neobarrosos del mismo modo en que la habría para el lunfardo, sino más bien destacar el interés de Perlongher por proponer una imitación literaria de determinados lenguajes alternos al estándar. De este modo, así como el lunfardo se asocia a ciertas formas de vida delictual, el neobarroso perlonghereano puede ser entendido como una lengua alegorizada de los sustratos lingüísticos asociados a una experiencia de exilio, dado que constituye un corpus lingüístico abigarrado de elementos que dan cuenta de una mixtura idiomática que refleja un trance transterritorial. En esta línea, "El rompehielos" demuestra hasta qué punto el neobarroso vacía sus enunciados de expresión comunicativa, quebrando las relaciones entre los sintagmas y haciendo una poesía del habla por medio de una interlengua sin gramática aparente.

\section{Pó́tica del trance Como morada de lenguas EVAnescentes}

La escritura neobarrosa desarrolla una reflexión sobre lenguajes sin escritura, incurriendo en un acto de fijación poética de lenguas no estandarizadas, así como también de las operaciones de generatividad y transformación lingüística que le son fuente de desarrollo. Perlongher no sólo se siente atraído por el portuńol y el lunfardo, sino que además por lo 
que éstos representan de manera más profunda: un acervo de palabras en constante movilización y riesgo de desaparición.

De esto deriva una dificultad particular al momento de llevar esta poesía a la experiencia de su lectura en voz alta. Dicho acto representó para Perlongher una oportunidad excepcional para ilustrar a viva voz la sorprendente cualidad musical de su escritura. Su lectura se caracterizaba por la utilización de tonos graves que variaban sorpresivamente hacia otros más agudos. Estos rasgos permiten pensar que el poeta consideraba el contexto de la lectura en voz alta como una instancia de explotación interpretativa del poema.

En esta línea, Andermann describe la dificultad que existiría en el caso de las escrituras que oscilan entre el portugués y español. Para esto toma como ejemplo Mar paraguayo, libro de Wilson Bueno sobre el cual observa:

Porque - para empezar por la cuestión del soporte mediático (voz o letra)Mar paraguayo construye una "voz oral” cuyo balbuceante vaivén entre lenguas pide a gritos la declamación en voz alta, al mismo tiempo que no es asequible sino a través de esta trans-cripción sin ley (como dice Perlongher, "hay una gramática, pero es una gramática sin ley; hay cierta ortografía, pero es una ortografía errática: chuvia y lluvia (grafadas de ambas maneras) pueden coexistir en el mismo párrafo...”). Al carecer de ley -o de código fonético-, entonces, esa escritura que dice ser eco de un habla se vuelve opaca y deja de entregarse transparentemente a una lectura "reproductora" de la voz original. No sabemos si pronunciar con inflexión castellana o portuguesa, encontrándonos -literalmente- en el espacio de ilegalidad de un habla migrante, exiliados de las leyes y las certezas de la lengua nacional. (Andermann, 2011, 14).

La observación de Andermann es muy valiosa, en la medida en que describe la manera como la interlengua poética y trashumante implica la 
desregulación de la pronunciación. La ausencia de un estatuto conocido que regle dicha acción depara la infracción de las leyes de pronunciación de la lengua de origen de los elementos heteroglósicos integrados al poema. Esta situación colabora con la preservación que hace el poema de su oscuridad semántica-opacidad al decir del crítico- la que comporta, al mismo tiempo, una segunda ilegalidad, la de frecuentar un lenguaje marginal estigmatizado. El lector es deparado a este equívoco por la convergencia caótica de elementos de lengua extranjera y la ausencia de referencias que permitan diferenciar con precisión la simple modificación, o invención de palabras, de la inclusión de elementos de una lengua no espańola.

En atención a la forma en la que se conforma la enunciación heteroglósica hasta aquí descrita, podríamos considerar que más que un tránsito a través de las lenguas no oficiales que interesaron a Perlongher, por su simbolismo marginal y contrasistémico, su escritura constituye una suerte de deriva idiomática, un extravío en las lenguas y en los territorios que éstas refieren. Volvemos aquí a la categoría de trance a la que parece corresponder el lenguaje desreglado que, en estos poemas, da cuenta de una intensa constricción interior, caracterizada por la confusión, el extravío y la problematización de los puntos de las referencias culturales a la que sería empujado el cuerpo en el exilio.

Ahora bien, resulta pertinente preguntarnos en este momento por la referencia que este tipo de textos hace al mundo, puesto que la poética del trance tendría el carácter de ensimismamiento autorreflexivo de manera simultánea a una referencialidad determinada por la alusión de los lenguajes de la realidad. Esto tendría lugar gracias a la inclusión de la noción de 
equívoco aparente que referiría, por una parte, a la ley en oposición a la cual los enunciados devendrían proposiciones erróneas - en este caso, la gramáticay, por otra parte, a la confrontación caótica de registros lingüísticos y lenguas heterogéneas en referencia a la diversidad de lenguas existentes.

Los errores y las interferencias lingüísticas constituyen fragmentos de la realidad que la escritura neobarrosa acoge. Éstos permiten abstraer la escritura perlonghereana de la deseable transparencia, presentándonos una lengua intersectada por segmentos de lenguas foráneas que dotan al texto literario de una porosidad que explicita así una suerte de bilingüismo. La visión de lenguas extranjeras que anegan la lengua materna define la relación que esta poesía describe con respecto a la realidad, específicamente, la transgresión de sus códigos lingüísticos.

En este sentido, estos poemas serían ejemplo de una intertextualidad abierta, en la medida en que constituyen un collage de elementos que organizan una mirada a la ley de la lengua, visibilizada a través de su infracción, refiriendo así la forma en que la gramática, más allá de regular la correcta realización de un idioma, instituye un dispositivo que instaura un mecanismo de control de los individuos. Esto es posible gracias a la supresión emotiva que propendería la lengua estándar, mediante el establecimiento de formas de expresión homogeneizante. Esta situación define a la poesía como un medio, quizás único, en la tarea de hacer posible una expresión genuina que, extremando sus mecanismos de generatividad, podría constituir un acto liberador. Con respecto a la génesis de las lenguas como maquinaria de opresión, Cangi desarrolló una lúcida reflexión de la que rescatamos el siguiente fragmento: 
Las lenguas nacionales a través de la pedagogía y el uso jurídico matrizan la subjetividad para liberarla de las particularidades históricas, sus costumbres locales, sus concepciones ancestrales, sus prejuicios y su lengua materna, es decir de su campo afectivo. La gramática es el sueño de una igualdad y un pacto de libertad que el Estado estructura como desigualdad real en la organización al acceso pedagógico. Las fuerzas migrantes, la diversidad no absorbida funciona como deriva amenazante que deja errar sus flujos sobre el cuerpo lleno de lenguaje. (Cangi, 2000, Poética, 266)

Esta descripción resulta fundamental para comprender la concepción de lenguaje a la que la poética del trance se enfrenta. En efecto, ésta parece buscar la forma de anular, a través de la escritura poética, la generación de matrices de subjetividad que determinan que toda expresión sea mediatizada por los moldes simbólicos que la lengua ha predeterminado. Ante esta conciencia, el poeta opone, en un gesto similar al que Cangi describe, la fuerza idiomática de la migración como un placebo de diversidad no absorbida, un léxico plural e insólito que se resiste a que los rasgos en los que se funda su particularidad sean abstraídos por la gramática dominante. Esto tiene como resultado la sindicación tácita de esta obra como un ejercicio libertario y profusamente desagradable a los ojos de la crítica aquiescente de la gramática normativa y de las literaturas estandarizadas.

En consideración de lo anterior, la interlengua neobarrosa se convierte en una verdadera vía de escape para las inquietudes políticas del poeta, al mismo tiempo que constituye el reflejo sintomático del trance de un cuerpo a través de las lenguas por las que trashuma instituyendo una confusión contrasistémica y antieconomicista a través de la subversión del equilibrio establecido por la lengua estándar y promovido, a su vez, por literaturas estandarizadas. Lo 
anterior define a la escritura perlonghereana como una herramienta apócrifa que constata la inestabilidad de la representación literaria.

La poética del trance parece responder a la idea de que el respeto del principio de economía en la expresión tiene como resultado una lengua que acalla la especificidad de la existencia individual y colectiva. La obra de Perlongher, en cambio, parece constituir un idioma que, en su profusión y caoticidad, parece exaltar la vida. Estas particularidades tienen como consecuencia el realce de la personalidad del autor a través de su escritura, situación determinada por la naturaleza de su enunciación en la que se transparenta una voluntad caprichosa, donde la palabra y el verso son arrojados sobre la página como un trazo de pintura grosero y voluminoso, fruto de un ímpetu artístico, aparentemente no racionalizado.

El tema de la heteroglosia en Perlongher constituye el ingreso de una inestabilidad que se extiende tanto en el plano semántico como en el de la dicción, aspectos que, de modo general, violentan los estatutos rectores del idioma base, el español. Estos asuntos corresponden, siguiendo a Cangi, al combate que el poeta mantiene con la matrificación de la subjetividad. En esta línea, su escritura puede ser entendida como la expresión del dominio de lo inefable, situación que estaría directamente ligada a una crítica sobre los principios económicos que ejercen su autoridad sobre el idioma.

Lo anterior tendría lugar gracias a la estandarización del habla a partir de un ideal de productividad y de manera más profunda, como indica Cangi, para otorgar referentes que se vuelven matrices modeladoras de la sensibilidad. Un buen ejemplo de esto y de cómo el portuñol en sí mismo 
es percibido como una lengua a perseguir - en virtud de su alejamiento de la manifestación estandarizada del portugués - es el conjunto de políticas lingüísticas definidas durante los ańos noventa con motivo de la firma del tratado del Mercosur:

Los empresarios brasileńos, ya en la etapa de puesta en marcha de tal tratado, se pronunciaron y el enunciado que concentró su postura podría ser algo así como Não basta o portunhol para fazer Mercosul. La emergencia de tal enunciado puede interpretarse como un acontecimiento discursivo porque le hace frente a una memoria a partir de las exigencias que impone una actualidad, interfiere en las rutinas del discurso y funda una nueva relación entre el brasileño y la lengua española. (Celada, 263, 2000, cursivas de la autora)

La situación descrita en este fragmento ilustra la lógica de jerarquización a la que son sometidas las lenguas en función de su mayor o menor grado de adecuación a los intereses nacionales de educación determinados, en gran medida, por criterios de mercado. Tal como apunta Celada, la fuerza de lo actual ejerce su poder sobre la memoria, en la medida en que el deseo de uniformización lingüística adquiere mayor relevancia que el estado de las lenguas determinado por la historia de los cuerpos que definen dicha manifestación lingüística. Este es un ejemplo de cómo el orden del Estado se impone sobre las contingencias del idioma y los trances corporales que le sirven de contexto.

La poesía de Perlongher estaría en una permanente lucha contra el poder ejercido por las economías sobre la vitalidad de las lenguas, a través de vocalizaciones que transparentan la íntima historia de los cuerpos en exilio o en situaciones excéntricas al poder. La escritura de Perlongher parece indicar 
que la vitalidad de la lengua no depende de la sujeción a la gramática de Estado y, por ende, a su supervivencia y difusión oficial, sino más bien a la utilización de lenguas móviles, evanescentes, exultantes de generatividad y, en consecuencia, subversivas.

En atención a lo anterior, podemos considerar que el poema "El rompehielos" es un ejemplo de cómo Perlongher busca, a través de su poesía, instaurar una especie de soberanía del habla, a través de la implicación de lenguas evanescentes. Este ejercicio determina la instalación de un pacto con la oralidad en tanto que fuente de hablas que reflejan la historia de los cuerpos, en tanto que lenguas alternas a la estándar y espacio de insumisión a los estatutos gramaticales.

\section{REFERENCIAS BIBLIOGRÁFICAS}

Andermann, Jens. "Abismos del tercer espacio: Mar paraguayo, portuñol salvaje y el fin de la utopía letrada”. In: Revista hispánica moderna, ISSN 0034-9593, Vol. 64, No 1, 2011, 11-22.

Augusto Lorenzino, Gerardo. "El lunfardo en la evolución del español argentino". In: Literatura y Lingüistica, Santiago, n. 34, 335-356, 2016. Disponible en: <https://scielo.conicyt.cl/scielo.php?script=sci_ arttext\&pid=S071658112016000200016\&lng $=$ es $\&$ nrm $=$ iso $>$. Consultado el 30 ago. 2020. http://dx.doi.org/10.4067/S0716-58112016000200016.

Andermann, Jens. "Abismos del tercer espacio: Mar paraguayo, portuñol salvaje y el fin de la utopía letrada”. In: Revista hispánica moderna, ISSN 0034-9593, Vol. 64, No 1, 2011, 11-22.

Cangi, Adrián. "Una poética bastarda”. In: Tsé-Tsé 7/8. Buenos Aires: Tsé-Tsé, 2000. 
Celada, María Teresa. “Acerca del errar por el portuñol”. In: Tsé-Tsé. Buenos Aires: Tsé-Tsé, 2000.

Centro Virtual Cervantes. Disponible en: http://cvc.cervantes.es/ensenanza/ biblioteca_ele/diccio_ele/diccionario/interlengua.htm. Consultado el 06 dic. 2012.

Cortázar, Julio. Rayuela. Caracas: Ayacucho, 2004.

Dicionário Priberam da Lingua Portuguesa. Disponible en: http://www.priberam.pt/ dlpo/default.aspx?pal=ling\%C3\%BCi\%C3\%A7a. Consultado el 11 nov. 2012.

Diccionario WordReference. Disponible en: http://www.wordreference.com/ptes/ ling\%C3\%BCi\%C3\%A7a. Consultado el 11 nov. 2012.

Gobello, José. Nuevo diccionario lunfardo. Buenos Aires: Corregido, 1999.

Hedelvio, Laurio. 100 años de un rescate épico en la Antártica. Buenos Aires: Instituto de Publicaciones Navales, 2003.

Klee, Carol; Lynch, Andrew. El español en contacto con otras lenguas. Washington: Georgetown University Press, 2009.

Perlongher, Néstor. Poemas completos. Buenos Aires: Seix Barral, 1997.

Reyes, Alfonso. La experiencia literaria. Buenos Aires: Losada, 1942. 